Research Article

\title{
Experimental Study for Influence of Surfactants Chemical Microstructures on Wetting Effect about Coal Dust in Tongchuan Mining Area
}

\author{
Youying Ma $\mathbb{D}^{1},{ }^{1}$ Yuying Wang $\mathbb{D}^{2,3}$ and Qingtao Zhang $\mathbb{D}^{2,3}$ \\ ${ }^{1}$ College of Chemical Engineering and Safety, Binzhou University, Binzhou 256600, China \\ ${ }^{2}$ College of Safety and Environmental Engineering, Shandong University of Science and Technology, Qingdao 266590, China \\ ${ }^{3}$ State Key Laboratory of Mining Disaster Prevention and Control Co-founded by Shandong Province and the \\ Ministry of Science and Technology, Shandong University of Science and Technology, Qingdao 266590, China \\ Correspondence should be addressed to Yuying Wang; 17866806426@163.com
}

Received 15 February 2020; Revised 22 April 2020; Accepted 25 June 2020; Published 31 July 2020

Academic Editor: Kaustubha Mohanty

Copyright (C) 2020 Youying Ma et al. This is an open access article distributed under the Creative Commons Attribution License, which permits unrestricted use, distribution, and reproduction in any medium, provided the original work is properly cited.

\begin{abstract}
Because of the unsatisfactory dust suppression efficiency, coal dust still threatens production safety and personnel health. In order to understand the influence of the chemical microstructures of the surfactant on the wetting ability and to facilitate the rapid selecting of surfactants with good wetting performances for specific coal dust, fatty acid methyl ester ethoxylate (FMEE), dodecyl dimethyl betaine (BS-12), sodium fatty acid polyoxyethylene ether carboxylate (AEC), and dodecyl dimethyl benzyl ammonium chloride (DDBAC) were selected in this paper to study the wetting ability of these four surfactants on the bituminous coal dust in Tongchuan, Shaanxi province of China. First, the main functional groups and carbon composition of the coal dust and surfactants were determined by Fourier transform infrared spectroscopy and carbon-13 nuclear magnetic resonance spectroscopy experiments. Second, the drop shape analysis system DSA100 was used to measure the equilibrium contact angle of the surfactant solution with a concentration of $0.06 \%$ on bituminous coal dust. The relationship between the chemical microstructures of surfactants and contact angles was analyzed, and the main influencing factors were obtained. The results showed that the contact angle of DDBAC on coal sample dust was the smallest. In addition, the contents of hydroxyl, aromatic ring carbon, unprotonated carbon, and bridged aromatic carbon in surfactants had significant linear correlations with wettability, and the increase of their contents would lead to the decrease of contact angle. According to the results of correlation analysis and curve fitting, the evaluation model of influencing factors on the wettability to bituminous coal dust was established.
\end{abstract}

\section{Introduction}

In recent years, a variety of new clean energy applications have been realized. However, coal is still one of the most important fossil fuels $[1,2]$, as statistics show that coal accounts for approximately $41 \%$ of energy used for power generation [3]. Dust is an inevitable product of coal mining and can be generated during blasting, cutting, loading, and unloading $[4,5]$. With the increases in mechanized mining practices, coal production can be maintained, so there is still a lot of coal dust produced in the process of mechanized production [6,7]. Inhalable coal dust can damage lung cells and cause pneumoconiosis. Coal dust explosions have also caused impressive casualties and property damage, reduce visibility in the workplace, and accelerate the wear rate of equipment and instruments, posing a potentially huge threat to production safety and occupational health $[8,9]$.

The use of fine droplets generated by spraying has become a common method used to capture coal dust particles and reduce the dust concentration in the working environment of coal mines [10]. However, when water is used as a wetting agent, the effect of controlling coal dust is not very good [11]. Therefore, international and domestic researchers have performed numerous studies on how to choose a suitable dust suppressant to improve the performance of spraying for dust control. By studying the characteristics of 
coal dust, researchers have found that different types of coals with different degrees of metamorphism contain hydrophobic functional groups, such as methyl groups, methylene groups, and aromatic hydrocarbons. As the degree of metamorphism increases, the proportion of hydrophobic functional groups in the coal increases [12]. Therefore, the hydrophobicity of coal is the main reason for the unsatisfactory performance of water in dust suppression [13]. Based on this conclusion, finding a dust suppressant that can improve the wettability of coal dust has become a research hotspot [14]. Guy et al. [15] studied the wetting behavior of organic liquids, such as hexane, oleic acid, and o-xylene, on coal by using the hydrophobicity of coal. However, in addition to their high cost, organic liquids have the disadvantages of polluting the environment, flammability, and strong adhesive strength and are not suitable for use in the workplace. On the other hand, environmentally friendly polymers usually contain a large number of hydrophilic groups [16], and the dust suppression materials prepared by modification or mixing not only solve some disadvantages of organic liquids but also increase the hydrophilicity of the material. However, the obtained product usually has a high viscosity [17]. Using sticky polymers by spray can cause serious wear of the droplets, resulting in poor particle capture, and is not suitable for spraying.

Surfactants have both hydrophilic and hydrophobic groups. Surfactants have lower molecular weights than polymer-based dust suppressants and a low viscosity in aqueous solutions and are thus ideal choices for efficient dust suppressants [18]. Surfactant can not only improve the efficiency of spraying for dust control [19], but also inject into the coal seam to reduce the amount of dust produced during coal mining [20]. In recent years, researchers have conducted some meaningful studies on the wetting behavior of surfactants on coal dust. Xu [21] used sodium dodecyl sulfate, sodium dodecyl sulfonate, and sodium dodecyl benzene sulfonate to understand the relationship between the structure of anionic sodium salt surfactants and the wetting performance of the surfactants on coal. The surface tension, wetting time, and adsorption density of the three surfactant solutions were measured. The study found that the hydrophilic-lipophilic balance value and type of the surfactant have a relatively great impact on the wetting time.

In addition, the relationship between the physicochemical characteristics of coal dust, such as the functional groups, particle size, and roughness, and the wetting performance of water on coal have also been reported [22]. However, the influence of the characteristic surfactant parameters on their wetting performance has not been proposed in existing studies, and there are fewer parameters involved. In this study, nonionic surfactants, amphoteric surfactant, anionic surfactants, and cationic surfactants were selected. The types and contents of the main functional groups in the coal samples and surfactants were obtained by Fourier transform infrared spectroscopy (FTIR) experiments, and the type and content of the carbon structure in the coal sample and surfactant coal were determined by carbon-13 nuclear magnetic resonance $\left({ }^{13} \mathrm{C}-\mathrm{NMR}\right)$ experiments. In addition to the contact angle formed by the surfactant solution and coal dust surface, the correlation of the functional groups and surfactant carbon structure with the contact angle was calculated and analyzed. Furthermore, based on the analysis results, a model of the factors influencing the wettability was established to determine the quantitative relationship between the chemical microstructures and the ability of the surfactant to wet bituminous coal dust.

\section{Materials and Methods}

2.1. Experimental Materials. The coal sample used in this study was bituminous coal collected from Tongchuan, Shaanxi province, China. Sampling was performed according to the procedures described in GB 4475-2008. After sampling, the coal samples were immediately sealed and stored in the dark to avoid oxidation. The collected coal sample was processed into experimental coal powder within 48 hours of sampling.

In this study, four different types of surfactants commonly used in coal processing were selected (Table 1). The reagents needed in the experiment included potassium bromide, deionized water, hydrochloric acid, hydrofluoric acid, and heavy water. The abovementioned reagents were purchased from Qingdao Jingke Co., Ltd.

2.2. Experimental Instruments. A XQM series planetary ball mill was used to crush bituminous coal into powder; a NicoletiS10 FTIR spectrometer was used to acquire the infrared spectra of the coal samples and surfactants; a BRUKER AVANCE III 400 NMR spectrometer was used to acquire the ${ }^{13} \mathrm{C}-\mathrm{NMR}$ spectra of the coal samples and surfactants; a powder tablet press was used to prepare briquettes with a diameter of $13 \mathrm{~mm}$ and a thickness of approximately $1 \mathrm{~mm}$ from the pulverized coal. The drop shape analysis system DSA100 was used to determine the contact angle.

\subsection{Experimental Methods and Principles}

2.3.1. Preparation of Pulverized Coal. The experimental coal powder was prepared using a planetary ball mill (Figure 1). The grinding duration did not exceed $2 \mathrm{~min}$ to prevent the coal samples from heating and oxidation. The coal powder was removed and sieved through a standard 200-mesh sieve to obtain the experimental coal powder. The pulverized coal was stored in a nitrogen-filled plastic bottle to prevent the pulverized coal from oxidizing, and the sample was stored in the dark at a low temperature.

2.3.2. FTIR Experimental Procedure. A Nicolet 380 FTIR spectrometer equipped with solid and liquid measurement units was used to study the solid and liquid samples (Figure 2). For the solid sample measurement, the sample to be tested and potassium bromide were thoroughly mixed and ground to achieve a 1:100 mass ratio, and the ground sample powder was formed into pellets with a powder tablet press. The compression pressure was $10 \mathrm{MPa}$, and the 
TABLE 1: Names and types of surfactants for experiments.

\begin{tabular}{lcc}
\hline No. & Name & Type \\
\hline 1 & Fatty acid methyl ester ethoxylate (FMEE) & Nonionic surfactant \\
2 & Dodecyl dimethyl betaine (BS-12) & Amphoteric surfactant \\
3 & Sodium fatty acid polyoxyethylene ether carboxylate (AEC) & Anionic surfactant \\
4 & Dodecyl dimethyl benzyl ammonium chloride (DDBAC) & Cationic surfactant \\
\hline
\end{tabular}

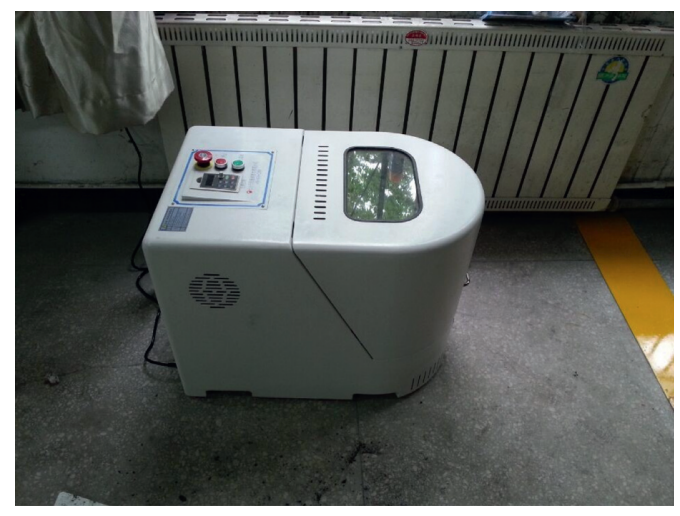

(a)

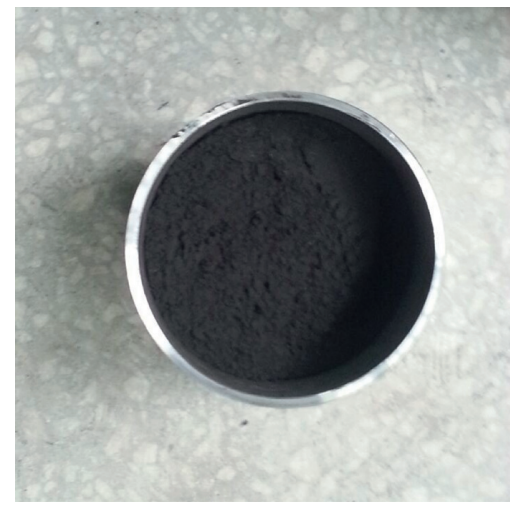

(b)

FIgURE 1: Preparation process of pulverized coal: (a) planetary ball mill; (b) pulverized coal and ball mill.

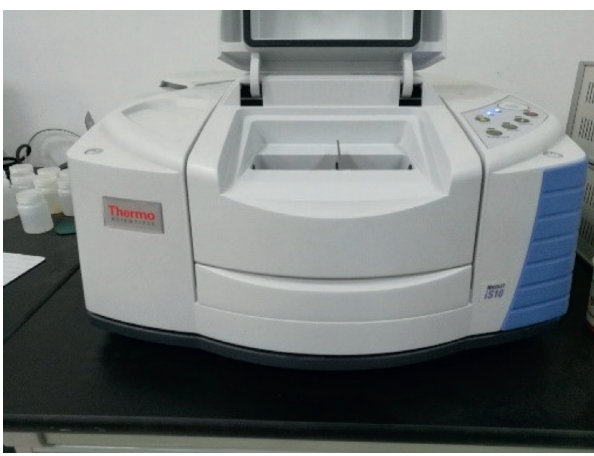

(a)

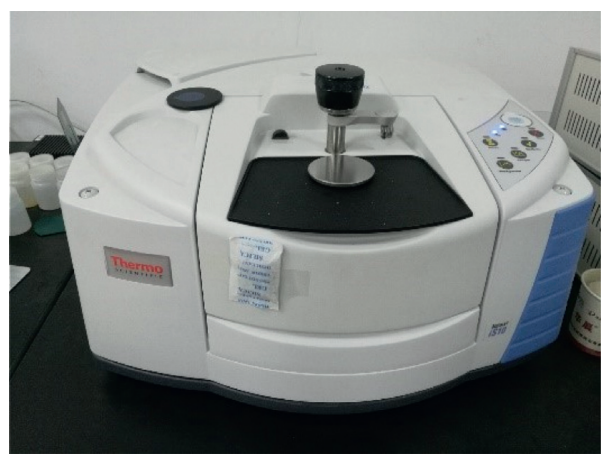

(b)

FIgURE 2: ThermoNicolet 380 Fourier transform infrared spectrometer: (a) solid analysis unit; (b) liquid analysis unit.

pressing duration was $2 \mathrm{~min}$. The liquid samples were both chemically and analytically pure, so no purification was required before the measurement.

\subsection{3. ${ }^{13}$ C-NMR Experimental Procedure. A Bruker Avance} III 400 NMR spectrometer was used for the high magnetic field solid-state ${ }^{13} \mathrm{C}-\mathrm{NMR}$ experiment (Figure 3 ). In the experiment, the samples were treated in three steps: deashing, grinding, and drying. In the deashing process, the coal sample was placed in a $300 \mathrm{ml}$ plastic beaker, a solution was prepared with a ratio of deionized water: $37 \%$ hydrochloric acid : 40\% hydrofluoric acid $=2: 1: 1$, and the reaction was carried out in a water bath at $50^{\circ} \mathrm{C}$ for 6 hours. The ratio used to prepare the solid surfactant was surfactant: heavy water $=20 \mathrm{mg}: 0.5 \mathrm{~mL}$, and the ratio used to prepare the liquid surfactant was surfactant : heavy water $=10 \mathrm{~mL}$ : $0.5 \mathrm{~mL}$. The poorly soluble surfactants were heated in a

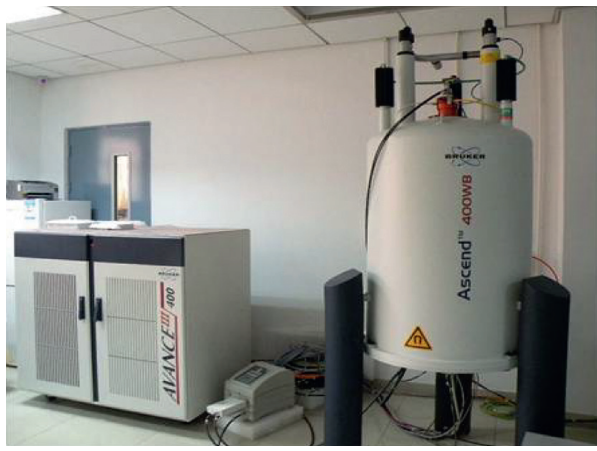

FIGURE 3: BRUKER AVANCE III 400 nuclear magnetic resonance instrument.

water bath, and the test tube was shaken to ensure that the sample was fully dissolved in heavy water to avoid inaccurate experimental results. 
2.3.4. Contact Angle Measurement Method. A powder tablet press was used to compress $300 \mathrm{mg}$ of the test coal dust under a pressure of $20 \mathrm{MPa}$ to prepare a standard cylindrical test piece with a diameter of $13 \mathrm{~mm}$ and a thickness of $1 \mathrm{~mm}$. The sample to be measured was fixed on the test platform of the DSA100 drop shape analysis system. Fast photography was employed, and the value of the contact angle was read by the instrument when the contact angle equilibrated. To improve the accuracy of the results, each experiment was repeated three times.

\section{Discussion and Analysis}

3.1. FTIR Analysis of the Coal Dust. The molecular structure of coal dust is very complex, and its wettability is strongly related to its internal molecular structure. FTIR has become a highly efficient tool for analyzing the molecular structure due to its low cost and fast and easy operation and is widely used to characterize the molecular structure of various complex products. In this study, the FTIR spectra of the coal dust are shown in Figure 4.

It can be seen from Figure 4 that a group of small sharp absorption peaks appeared in the characteristic peak region of $3500 \mathrm{~cm}^{-1}-3650 \mathrm{~cm}^{-1}$ and may be the absorption band generated by the stretching vibration of the hydroxyl group $(-\mathrm{OH})$ in phenol. The absorption peak at $2895 \mathrm{~cm}^{-1}$ is the absorption band of $-\mathrm{CH}$, the peak near $3070 \mathrm{~cm}^{-1}$ corresponds to the absorption of - $\mathrm{CH}$ in the benzene ring, and the peak near $3020 \mathrm{~cm}^{-1}$ is associated with the stretching vibration of the methine group on the aromatic ring. The peaks between $1500 \mathrm{~cm}^{-1}-1650 \mathrm{~cm}^{-1}$ are mainly related to the vibration of double bonds. Among them, the peak near $1550 \mathrm{~cm}^{-1}$ represents the vibration of $\mathrm{C}=\mathrm{C}$ in aromatic hydrocarbons, and the peak near $1700 \mathrm{~cm}^{-1}$ represents the vibration of carbonyl groups. The peaks at $950 \mathrm{~cm}^{-1}-1300 \mathrm{~cm}^{-1}$ are caused by the stretching vibrations of oxygen-containing functional groups and the stretching vibrations of $\mathrm{C}-\mathrm{N}$ functional groups. Among them, the peaks near $1300 \mathrm{~cm}^{-1}$ and $1250 \mathrm{~cm}^{-1}$ are due to the vibration of $\mathrm{C}-\mathrm{N}$ in fatty amines and the asymmetric stretching vibration of C-O-, respectively. From the peak information table of the bituminous coal FTIR spectra, it can be seen that the vibrational absorption peaks of the carbon-oxygen single bond, ether group, and hydroxyl group in the coal dust are more distinct than the other functional groups.

In addition, fitting of infrared spectrum peaks was used to further analyze the peaks of the spectra, which could yield not only the detailed peak position and functional group information but also the relative content of functional groups, providing a semiquantitative method of studying the functional groups and wettability of coal. The peak separation results of the bituminous coal samples used in the experiment are shown in Figure 5, and the positions and assignments of the peaks obtained from the peak separation are shown in Table 2.

Table 2 shows that the peaks found in the wavenumber range of $715 \mathrm{~cm}^{-1}-920 \mathrm{~cm}^{-1}$ are mainly generated by aromatic hydrocarbons, and the peaks found in the wavenumber range of $920 \mathrm{~cm}^{-1}-1400 \mathrm{~cm}^{-1}$ are mainly generated

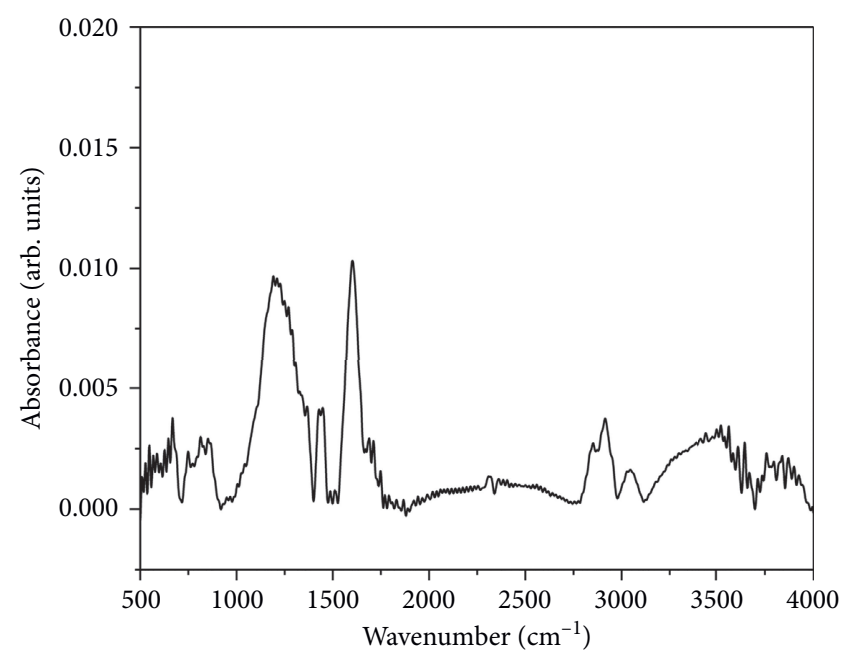

FIgURe 4: FTIR of bituminous coal dust.

from ether groups, hydroxyl groups, and fatty amines. In the wavenumber range of $1400 \mathrm{~cm}^{-1}-1720 \mathrm{~cm}^{-1}$, the spectrum was divided into 9 peaks, which are mainly generated by the vibration of aromatic hydrocarbons and aliphatic hydrocarbons. In the wavenumber range of $2775 \mathrm{~cm}^{-1}-3115 \mathrm{~cm}^{-1}$, vibrations of aromatic hydrocarbons and $\mathrm{C}=\mathrm{O}$ were detected. In the wavenumber range of $3117 \mathrm{~cm}^{-1}-3700 \mathrm{~cm}^{-1}$, the spectrum was divided into 9 peaks, which are due to the hydroxyl groups in the coal sample. These results suggest that the functional group composition of the coal dust is complex, and there are multiple types of hydrophilic functional groups and hydrophobic functional groups.

3.2. ${ }^{13} \mathrm{C}-\mathrm{NMR}$ Analysis of the Coal Dust. The spectrum obtained by the ${ }^{13} \mathrm{C}-\mathrm{NMR}$ experiment can provide the structural parameters of samples, which mainly contain various aromatic carbon structures and aliphatic carbon structures. Therefore, to determine the relative carbon content of the different structures, the peaks overlapping in the obtained spectrum should be reasonably separated. In this study, the Gaussian function and the Lorentzian function were used to process the smooth peaks and sharp peaks, respectively. The NMR spectra and fitting results of the coal samples are shown in Figure 6.

As shown in Figure 6, the ${ }^{13} \mathrm{C}-\mathrm{NMR}$ experimental result of the coal dust evaluated in the experiment was divided into 16 individual peaks. The chemical shifts, peak heights, peak widths, relative areas, and carbon atom assignment information obtained from the peak separation are shown in Table 3.

As shown in Table 3, there are numerous types of carbon atoms in the coal dust, including the aliphatic methyl groups, methylene groups, quaternary carbon, oxygen-linked aliphatic carbon, protonated aromatic carbon, bridged aromatic carbon, side-branched aromatic carbon, oxygen-linked aromatic carbon, carboxyl carbon, and carbonyl carbon. Among these carbon types, protonated aromatic carbon exhibited the highest content, followed by the methylene groups, quaternary carbon, bridged aromatic carbon, side-branched aromatic carbon, 


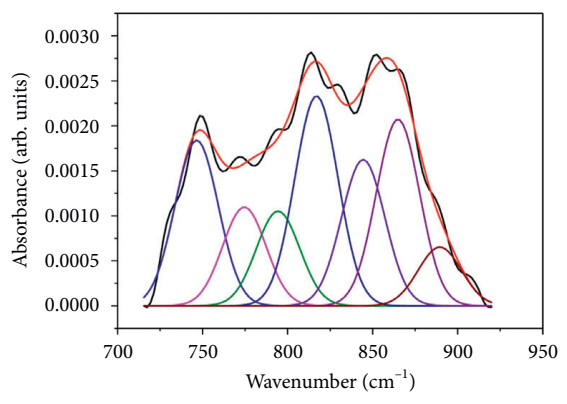

(a)

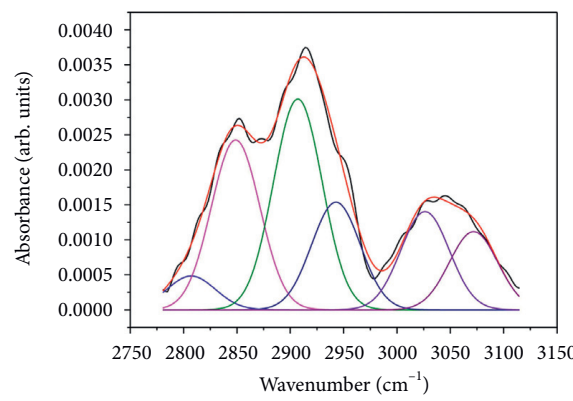

(d)

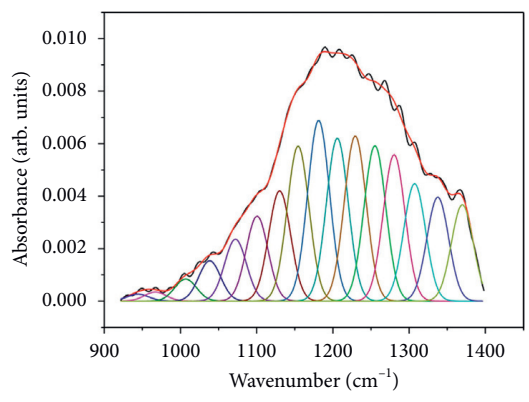

(b)

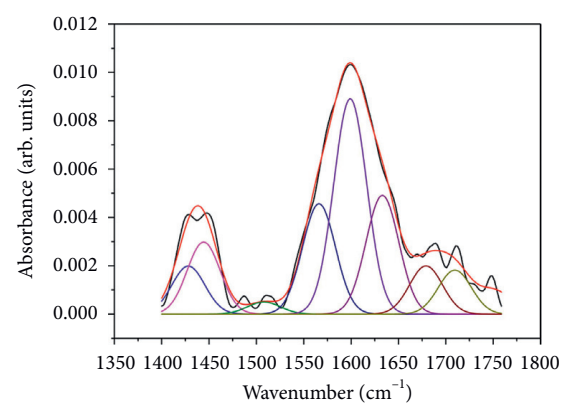

(c)

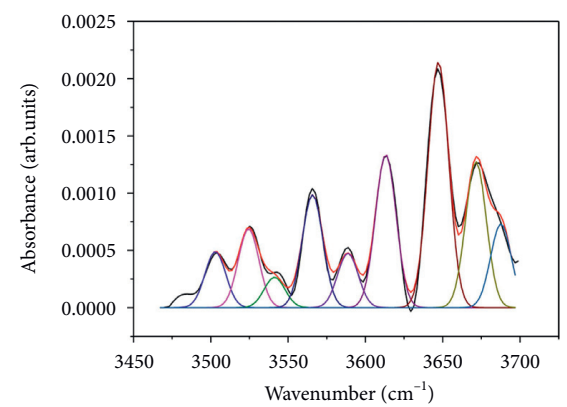

(e)

Figure 5: FTIR of bituminous coal dust. (d) $2775 \mathrm{~cm}^{-1}-3115 \mathrm{~cm}^{-1}$; (e) $3117 \mathrm{~cm}^{-1}-3700 \mathrm{~cm}^{-1}$.
(a) $715 \mathrm{~cm}^{-1}-920 \mathrm{~cm}^{-1}$;
(b) $920 \mathrm{~cm}^{-1}-1400 \mathrm{~cm}^{-1}$;
(c) $1400 \mathrm{~cm}^{-1}-1720 \mathrm{~cm}^{-1}$;

TABLE 2: FTIR peak assignment and position of bituminous coal dust $\left(\mathrm{cm}^{-1}\right)$.

\begin{tabular}{|c|c|c|c|c|c|c|c|c|}
\hline \multicolumn{2}{|c|}{$\begin{array}{l}\text { Aromatic } \\
\text { hydrocarbon }\end{array}$} & \multirow{2}{*}{$\begin{array}{c}\text { Aliphatic hydrocarbon } \\
889.49\end{array}$} & \multirow{2}{*}{$\begin{array}{c}\text { C-O- } \\
1205.76\end{array}$} & \multirow{2}{*}{$\begin{array}{c}\mathrm{C}=\mathrm{O} \\
1679.14\end{array}$} & \multirow{2}{*}{$\begin{array}{c}\text { Ether group } \\
1072.21\end{array}$} & \multicolumn{2}{|c|}{$-\mathrm{OH}$} & \multirow{2}{*}{$\begin{array}{c}\text { Aliphatic amine } \\
1280.30\end{array}$} \\
\hline 746.53 & 1428.16 & & & & & 967.08 & 3541.25 & \\
\hline 774.56 & 1507.95 & 1444.32 & 1229.27 & 1709.61 & 1100.56 & 944.18 & 3565.82 & 1307.21 \\
\hline 794.40 & 1566.07 & 1633.06 & 1038.39 & 1752.38 & 1130.10 & 1006.79 & 3588.64 & 1337.60 \\
\hline 816.96 & 1599.07 & 2848.76 & & 2807.01 & 1255.11 & 1154.30 & 3613.16 & 1369.82 \\
\hline 844.42 & 3026.33 & 2907.07 & & & & 1181.21 & 3647.23 & \\
\hline \multirow[t]{2}{*}{864.88} & 3071.84 & 2942.80 & & & & 3502.97 & 3671.52 & \\
\hline & & & & & & 3524.46 & 3687.67 & \\
\hline
\end{tabular}

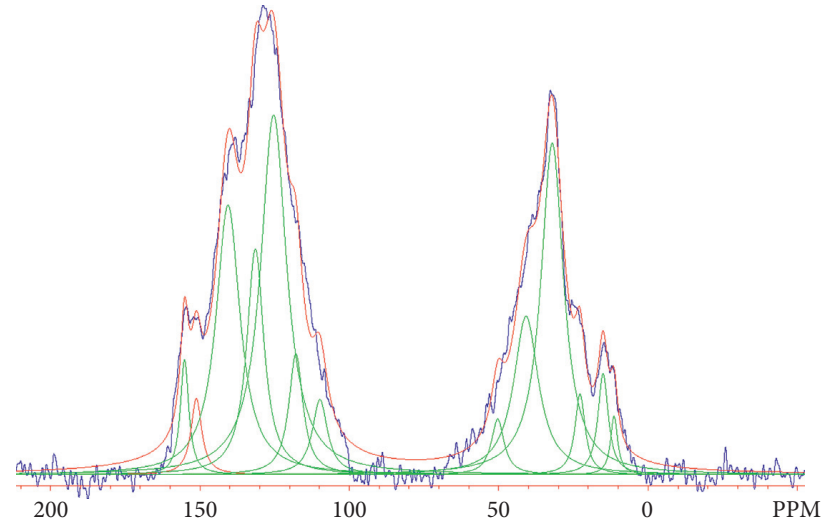

Figure $6:{ }^{13} \mathrm{C}$-NMR spectrum of bituminous coal dust.

and oxygen-linked aromatic carbon, and the contents of the carboxyl carbon, carbonyl carbon, and oxygen-linked aliphatic carbon were relatively low.
3.3. FTIR Analysis of the Surfactants. The FTIR results of the four surfactants obtained according to the FTIR measurement method described in 2.3.2 are shown in Figure 7. By comparing the spectra shown in Figure 7, it can be seen that the types of functional groups contained in the different surfactants were different, and the proportion of each functional group content was also considerably different. Compared to the spectra obtained for the other surfactants, the spectrum of dodecyl dimethyl betaine showed a relatively low number of peaks, and the functional group composition was relatively simple. The dodecyl dimethyl benzyl ammonium chloride spectrum comprised a high number of peaks and exhibited significant differences in the range of $3000 \mathrm{~cm}^{-1}-3500 \mathrm{~cm}^{-1}$ relative to the spectra of the other three surfactants. To obtain more detailed functional group data, the abovementioned spectra were subjected to FTIR peak separation according to the method mentioned in Section 3.1, and the peak separation results were subjected to assignment and statistical analyses. The types and relative 
TABLE 3: Percentages of different carbon types in ${ }^{13} \mathrm{C}$-NMR spectra of the coal dust.

\begin{tabular}{lccc}
\hline No. & ${ }^{13} \mathrm{C} / \delta \mathrm{ppm}$ & Area $(\%)$ & Assignment \\
\hline 1 & 16.356 & 5.20 & Aromatic methyl groups \\
2 & 23.275 & 2.18 & Methylene groups \\
3 & 32.222 & 11.20 & Methylene groups \\
4 & 40.030 & 7.48 & Quaternary carbon \\
5 & 46.753 & 5.34 & Quaternary carbon \\
6 & 54.118 & 0.29 & Oxygen-linked aliphatic carbon \\
7 & 112.792 & 3.62 & Protonated aromatic carbon \\
8 & 118.802 & 8.60 & Protonated aromatic carbon \\
9 & 128.262 & 31.86 & Protonated aromatic carbon \\
10 & 137.363 & 9.05 & Bridged aromatic carbon \\
11 & 143.595 & 9.05 & Side-branched aromatic carbon \\
12 & 151.576 & 3.46 & Oxygen-linked aromatic carbon \\
13 & 156.617 & 2.66 & Oxygen-linked aromatic carbon \\
14 & 181.383 & 1.24 & Carboxyl carbon \\
15 & 192.122 & 0.66 & Carbonyl carbon \\
\hline
\end{tabular}

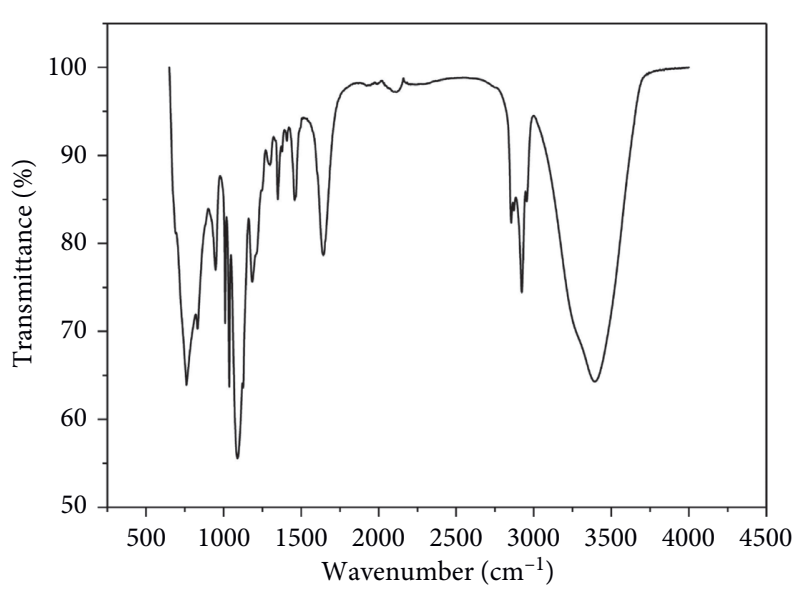

(a)

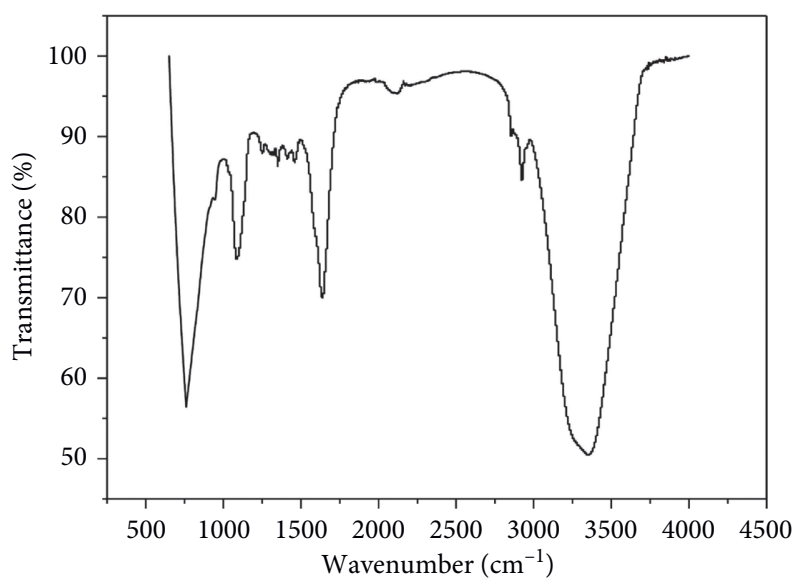

(c)

Figure 7: FTIR spectrum of surfactants. (a) FMEE. (b) BS-12. (c) AEC. (d) DDBAC.

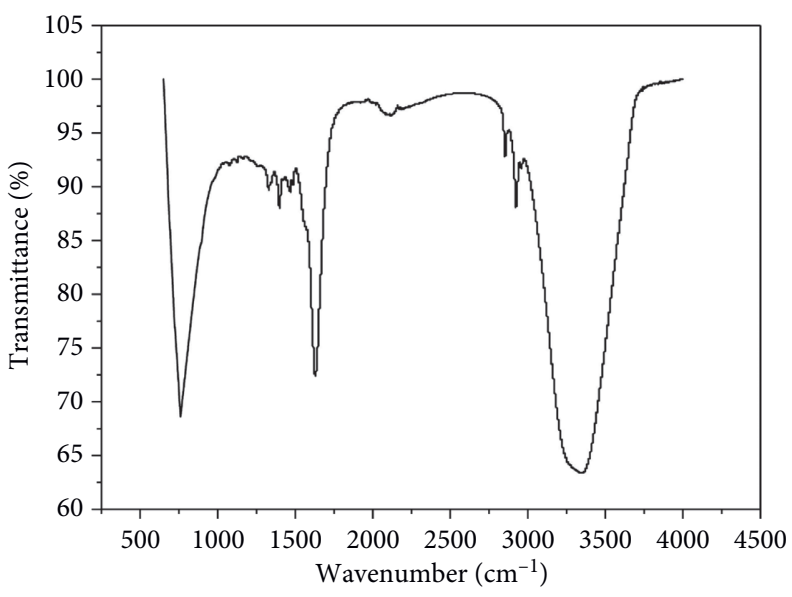

(b)

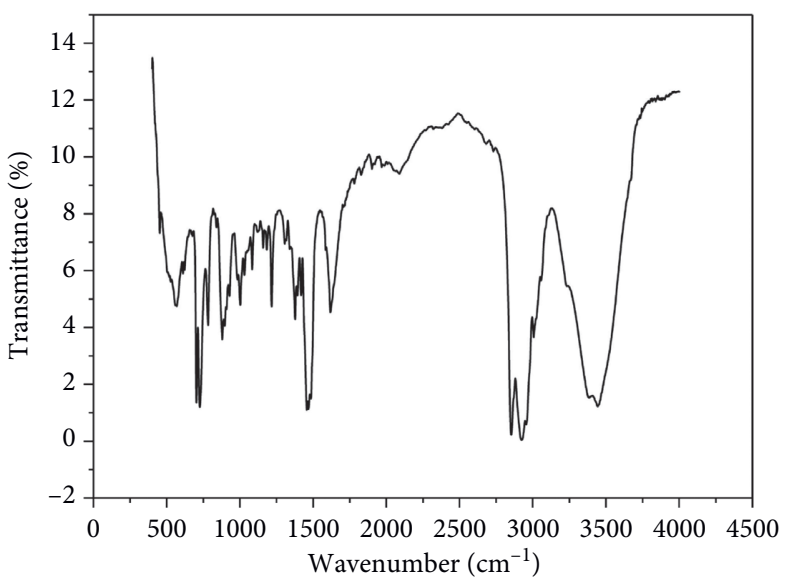

(d) contents of the main functional groups in each surfactant are shown in Table 4.

As shown in Table 4, the content of the aliphatic hydrocarbons in FMEE was higher than that of the aromatic hydrocarbon, and the functional group with the highest content was aliphatic hydrocarbons. The content of the aliphatic hydrocarbons in BS-12 was also greatly higher than that of the aromatic hydrocarbon, and dodecyl dimethyl 
TABle 4: Percentages of different functional groups in FTIR spectra of surfactants.

\begin{tabular}{lccccccccc}
\hline No. & $\begin{array}{c}\text { Aliphatic } \\
\text { hydrocarbon (\%) }\end{array}$ & $\begin{array}{c}\text { Aromatic } \\
\text { hydrocarbon (\%) }\end{array}$ & $\begin{array}{c}\text { C-O- } \\
(\%)\end{array}$ & $\begin{array}{c}\mathrm{C}=\mathrm{O} \\
(\%)\end{array}$ & $\begin{array}{c}\text { Ether } \\
\text { group (\%) }\end{array}$ & $\begin{array}{c}-\mathrm{OH} \\
(\%)\end{array}$ & $\begin{array}{c}\text { COO } \\
(\%)\end{array}$ & $\begin{array}{c}\text { Aliphatic } \\
\text { amine }(\%)\end{array}$ & $\begin{array}{c}\text { Aromatic amine } \\
(\%)\end{array}$ \\
\hline 1 & 59.3342 & 10.5399 & 9.8333 & 5.7475 & 4.8849 & 6.0026 & 0.2042 & 2.5728 & 0.8801 \\
2 & 56.7262 & 30.5618 & 0 & 1.8192 & 0 & 1.3143 & 1.4762 & 7.8322 & 0.2698 \\
3 & 60.1029 & 19.8547 & 3.5540 & 0 & 0.2249 & 7.7037 & 0.2466 & 7.7472 & 0.5656 \\
4 & 47.7413 & 15.6685 & 0 & 2.6994 & 0.5950 & 32.3666 & 0.3203 & 0.4054 & 0.2034 \\
\hline
\end{tabular}

betaine did not contain ether groups and C-O-. In AEC, the functional group with the highest content was the aliphatic hydrocarbons, followed by the aromatic hydrocarbon content, and AEC did not contain $\mathrm{C}=\mathrm{O}$. The content of aliphatic hydrocarbons in DDBAC was higher than that of aromatic hydrocarbons, and DDBAC did not contain ether group. Unlike the results obtained for the first three surfactants, the content of hydroxyl in DDBAC is relatively high.

3.4. ${ }^{13} \mathrm{C}-\mathrm{NMR}$ Analysis of the Surfactants. The ${ }^{13} \mathrm{C}-\mathrm{NMR}$ experimental procedure used for the surfactant was the same as that used for the coal. However, the molecular weight of the surfactant is smaller, and the surfactant structure is considerably less complex than that of coal. In this paper, the peaks in the ${ }^{13} \mathrm{C}$-NMR spectrum of the sample were separated to obtain the carbon structural parameters of the surfactant, as shown in Table 5.

Table 5 shows that most of the carbons in the surfactant were aliphatic carbons; $f_{a l}^{*}$ represents the relative content of the methyl group, $f_{a l}^{H}$ represents the relative contents of the quaternary carbon, methylene groups, and methine group, and $f_{a l}^{O}$ represents the content of aliphatic carbon attached to oxygen. Surfactants have fewer aromatic carbon structures, and BS-12 and AEC do not contain aromatic ring structures. In FMEE, the $f_{a l}^{H}$ in the fatty carbon structure was relatively high, indicating that $\mathrm{AEC}$ has a large number of branched structures. Meanwhile, the $f_{a l}^{O}$ component was dominant, indicating that FMEE contains a large amount of oxygen. The $f_{a l}^{H}$ component in BS-12 was dominant, but the content of methyl groups was relatively low, indicating that although BS-12 has a high number of branched structures, most of the structures at the end of the branched chains are connected to oxygen-linked carbon. The structure of AEC is similar to that of FMEE, and the branched chain structure of AEC is more abundant. In addition, the fatty carbon structure of DDBAC is similar to that of BS-12. The aromatic carbon structure content of DDBAC was the highest among the surfactants selected. Among the studied functional groups, the protonated carbon content was $4.48 \%$, the unprotonated carbon content was $29.06 \%$, and all the unprotonated carbons were bridged aromatic carbons. This indicates that the aromatization degree of DDBAC is relatively high and stable.

\section{Analysis of the Factors Influencing the Wettability of Surfactants on Bituminous Coal Dust}

4.1. Contact Angle Measurement. Coal dust is wetted by a surfactant solution by a process in which the solid-liquid interface gradually replaces the solid-gas interface. This process is a result of the combined action of microscopic characteristics, including the structure and properties of the solid surface, the properties of the liquid surface and interface, and the interaction between molecules in the solid and liquid phases. According to the analysis described in Sections 3.1 and 3.2, the experimental coal dust possesses complex microstructures, and there are multiple hydrophobic and hydrophilic structures. When the surfactant used for dust suppression changes, the hydrogen bonds and van der Waals forces formed between coal dust and the water molecules/surfactant molecules also change, eventually resulting in different dust suppression efficiencies. This study will evaluate the differences between the abilities of the different surfactants to wet bituminous coal dust and establish a mathematical model of the surfactant microstructure and wetting performance.

The contact angle formed by the liquid and solid surface can be used to determine the degree of wetting on the solid by the liquid. If the droplet can wet the solid, the contact angle is an acute angle; if the droplet cannot wet the solid, the contact angle is an obtuse angle. The contact angles of four surfactants on the surface of the coal dust were measured by the drop shape analysis system (DSA100) and are shown in Figure 8.

As shown in Figure 8, the contact angles of the surfactant droplet on the coal sample surface were different. Based on the critical micelle concentration and cost of each surfactant, a surfactant solution with a mass fraction of $0.06 \%$ was prepared, and the contact angle of the solution on the coal dust was measured. When the droplet spread and stabilized, the contact angle was measured, and the average of three measurements was calculated, as shown in Table 6.

The contact angle of BS-12 on the experimental coal sample dust was the largest, the contact angles of the surfactants FMEE and AEC on the experimental coal sample dust were relatively large, and the contact angle of DDBAC on the experimental coal sample dust was significantly smaller than those of the other three surfactants. The abovementioned results indicated that DDBAC exhibited the optimal ability to wet the bituminous coal dust.

\subsection{Effect of the Surfactant Functional Groups on Wetting} Bituminous Coal Dust. To determine the relationship between the functional group content and the wetting performance, the correlation between the functional group content of the surfactant and the wettability was analyzed according to the functional group content obtained from the peak separation and the experimentally measured contact angles, as shown by Table 7 . 
TABLE 5: Percentages of different carbon types in ${ }^{13} \mathrm{C}-\mathrm{NMR}$ spectra of the surfactants.

\begin{tabular}{lccccccccccc}
\hline No. & $f_{a}$ & $f_{a}^{C}$ & $f_{a}^{\prime}$ & $f_{a}^{N}$ & $f_{a}^{H}$ & $f_{a}^{S}$ & $f_{a}^{B}$ & $f_{a l}$ & $f_{a l}^{*}$ & $f_{a l}^{H}$ & $f_{a l}^{O}$ \\
\hline 1 & 6.90 & - & 6.90 & 1.51 & 5.39 & 1.51 & - & 93.10 & 4.76 & 19.98 \\
2 & 8.93 & 8.93 & - & - & - & - & - & 91.07 & 4.43 & 61.22 & 25.42 \\
3 & 2.27 & 2.27 & - & - & - & - & - & 97.73 & 3.42 & 31.49 & 62.82 \\
4 & 33.54 & - & 33.54 & 29.06 & 4.48 & - & 29.06 & 66.46 & 5.27 & 41.62 & 19.57 \\
\hline
\end{tabular}

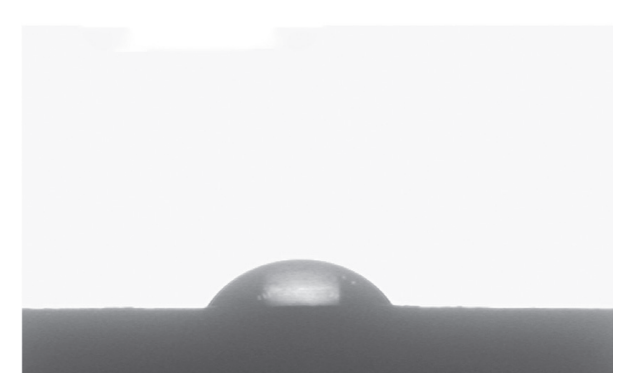

(a)

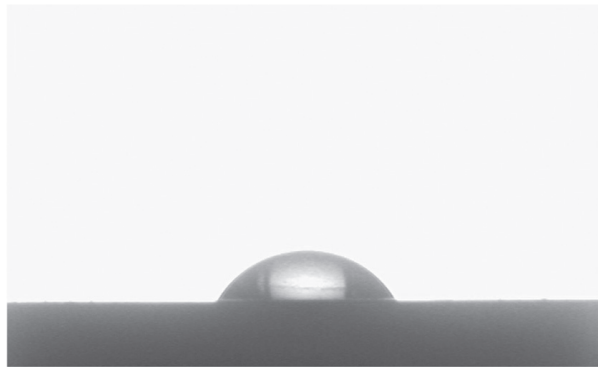

(c)

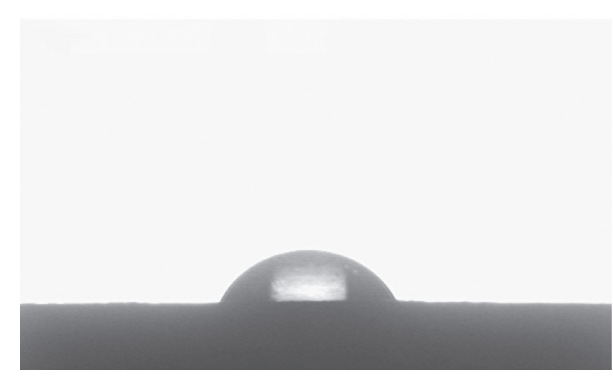

(b)

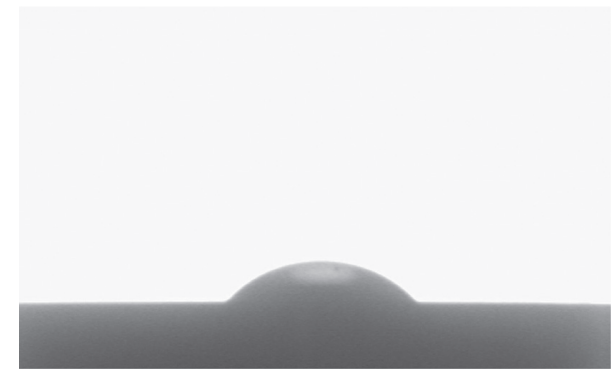

(d)

FIGURE 8: Contact angles of surfactants on the coal sample dust. (a) FMEE $41.79^{\circ}$. (b) BS-12 $48.07^{\circ}$. (c) AEC $43.73^{\circ}$. (d) DDBAC $24.13^{\circ}$.

TABLE 6: Contact angles of surfactants on the coal sample dust.

\begin{tabular}{llllr}
\hline No. & FMEE & BS-12 & AEC & \\
\hline 1 & $43.48^{\circ}$ & $45.97^{\circ}$ & $43.73^{\circ}$ & $23.76^{\circ}$ \\
2 & $41.15^{\circ}$ & $48.07^{\circ}$ & $44.55^{\circ}$ & $24.13^{\circ}$ \\
3 & $41.79^{\circ}$ & $48.61^{\circ}$ & $45.37^{\circ}$ & $24.14^{\circ}$ \\
Avg. & $42.00^{\circ}$ & $47.55^{\circ}$ & $44.55^{\circ}$ & $24.01^{\circ}$ \\
\hline
\end{tabular}

TABLE 7: Linear correlation analysis of wettability and surfactant functional group parameters.

\begin{tabular}{|c|c|c|c|c|c|c|c|c|c|c|c|}
\hline & & $\begin{array}{l}\text { Contact } \\
\text { angle }\end{array}$ & $\begin{array}{c}\text { Aliphatic } \\
\text { hydrocarbon }\end{array}$ & $\begin{array}{c}\text { Aromatic } \\
\text { hydrocarbon }\end{array}$ & C-O- & $\mathrm{C}=\mathrm{O}$ & $\begin{array}{l}\text { Ether } \\
\text { group }\end{array}$ & $-\mathrm{OH}$ & $-\mathrm{COO}$ & $\begin{array}{l}\text { Aliphatic } \\
\text { amine }\end{array}$ & $\begin{array}{c}\text { Aromatic } \\
\text { amine }\end{array}$ \\
\hline \multirow{3}{*}{$\begin{array}{l}\text { Contact } \\
\text { angle }\end{array}$} & $\begin{array}{c}\text { Pearson } \\
\text { correlation }\end{array}$ & 1 & 0.903 & 0.473 & 0.699 & 0.081 & 0.332 & $-0.989 *$ & 0.443 & 0.856 & 0.409 \\
\hline & $\begin{array}{l}\text { Sig. }(2- \\
\text { tailed) }\end{array}$ & & 0.097 & 0.527 & 0.507 & 0.948 & 0.785 & 0.011 & 0.557 & 0.144 & 0.591 \\
\hline & $N$ & 4 & 4 & 4 & 3 & 3 & 3 & 4 & 4 & 4 & 4 \\
\hline
\end{tabular}

As shown in Table 7, the content of -OH was negatively correlated with the contact angles, and the other functional groups, such as the aromatic hydrocarbons, C-O-, aliphatic hydrocarbon, and aliphatic amines, were positively correlated with the contact angles. The correlation coefficient between $-\mathrm{OH}$ content and contact angle was -0.989, showing a significant negative correlation. This may be due to the high polarity and hydrophilicity of hydroxyl group. According to the FTIR spectra of coal samples, the surface of coal is mainly hydrophobic functional group. Hydroxyl can not only increase the difference of hydrophilicity and hydrophobicity between the two ends of surfactant, but also 
reduce the surface free energy of solution and may form hydrogen bond with oxygen-containing functional groups on the surface of coal dust. Therefore, the higher hydroxyl content is more conducive to the spread of droplets on the coal dust surface, and the contact angle measured by the experiment is smaller. In addition, the correlation between the aliphatic hydrocarbon and the contact angle was significant, and the correlation coefficient of the carbonyl group with the contact angle was the lowest.

A correlation analysis can only determine the degree of linear correlation between factors. Therefore, polynomial regression was performed on factors that showed a poor linear correlation with the wettability, and whether other types of mathematical models could be established between these factors and the wettability was explored. According to Table 7, the ether group, -COO, aromatic hydrocarbon, and aromatic amine contents were selected for the polynomial regression. The highest order of regression was 2 , and the mathematical model established is shown in Table 8.

According to Table 8, the ether group, - $\mathrm{COO}$, aromatic amine, and aromatic hydrocarbon contents were all used to establish a quadratic polynomial relationship with the contact angle, but the degree of fitting achieved by the models varied greatly. The $R^{2}$ value of the ether group was greater than 0.9 , indicating a good model fit and a strong secondary correlation between the ether group content and the contact angle. The $R^{2}$ values obtained by fitting the models of the other three factors were small, indicating that the fitting results of the models are not ideal, and the quadratic correlation between the factors and the contact angle is weak.

\subsection{Effect of the Surfactant Carbon Structure on Wetting} Bituminous Coal Dust. According to the NMR peak separation results of the surfactants, the linear correlation between the carbon structural parameters of the surfactants and the wettability was analyzed. The results are shown in Table 9.

As shown in Table 9, the correlation coefficient between the aromatic ring carbon content and the contact angle was the highest $(-0.993)$, indicating that there is a very significant negative correlation between the aromatic ring carbon content and the contact angle. In addition, the correlation coefficients between the unprotonated carbon/bridged aromatic carbon content and the contact angle were high, suggesting a significant negative correlation. The correlation coefficients between the quaternary carbon/methylene content and the contact angle were only 0.095, indicating that there is almost no linear correlation between the quaternary carbon/methylene content and the contact angle. Aromatic ring is a kind of polar hydrophobic group. Although its hydrophobicity is slightly lower than that of aliphatic alkanes, its ability to form hydrogen bond is stronger. It can be seen from Table 3 that protonated carbon and bridged aromatic carbon in coal dust are high, and aromatic carbon is the main part of coal dust carbon. When the nonprotonated carbon, bridging aromatic carbon, and other aromatic carbon structures in surfactants contact with the coal dust surface, hydrogen and ion bonds may be formed between the molecules due to protonation and polarization.
TABLE 8: Nonlinear correlation analysis of surfactant functional groups and wettability.

\begin{tabular}{lcc}
\hline Factor & Fitting formula & $R^{2}$ \\
\hline Ether group & $Y=50.14-46.35 x+9.15 x^{2}$ & 0.91375 \\
-COO & $Y=89.48-243.5 x+145.7 x^{2}$ & 0.82253 \\
Aromatic amine & $Y=10.92+123.68 x-101.67 x^{2}$ & 0.43282 \\
Aromatic hydrocarbon & $Y=56.02-2.45 x+0.07 x^{2}$ & 0.34614 \\
\hline
\end{tabular}

The combination and adsorption of surfactant and coal are conducive to the spread of droplets on the surface of coal dust, so the increase of aromatic carbon content in surfactant will form a small contact angle. To further analyze the relationship between the carbon structural parameters and the wettability, carbonyl carbon, protonated carbon, aliphatic methyl/arylmethyl, quaternary carbon/methylene, and oxygen-linked aliphatic carbon, with weak linear correlations were selected to perform the secondary correlation analysis, and the fitting results are shown in Table 10.

According to Table 10, the five abovementioned sets of parameters could all be used to establish a nonlinear mathematical model with the wettability, but some of the models fit poorly. The $R^{2}$ values of the models used to fit the relationship between the protonated carbons and the wettability and the relationship between the aliphatic methyl/ arylmethyl content and the wettability were very close to 1 , indicating a good model fit. However, the $R^{2}$ value of the model used to fit the relationship between the quaternary carbon/methylene content and the wettability was only 0.46883 , and the fitting result was not ideal.

4.4. Model Evaluating the Factors Influencing the Wettability of Bituminous Coal. According to the linear and nonlinear correlation analysis shown in Sections 4.2 and 4.3, compared to the other functional groups, the hydroxyl content exhibited a significant linear correlation with the wettability, and the ether group content exhibited a good polynomial correlation with the wettability. Among the carbon structural parameters, the aromatic ring carbon and unprotonated carbon contents showed a significant linear correlation with the wettability, while the fatty methyl group, arylmethyl group, and protonated carbon contents could establish good polynomial correlations with the wettability. Therefore, the abovementioned main influencing factors were selected to construct the model used to evaluate the factors influencing the wettability, and the values assigned to the variables are shown in Table 11.

According to the relationship between the factors and the contact angle obtained from the abovementioned analysis, the correlation equation was established as follows:

$$
\begin{aligned}
Z= & a+b * x_{1}+c * x_{2}+d * x_{3}+e * x_{4}+f * y_{1}+g * y_{1}^{2} \\
& +h * y_{2}+i * y_{2}^{2}+j * y_{3}+k * y_{3}^{2} .
\end{aligned}
$$

A fitting function was used to perform the nonlinear curve fitting of the self-defined formula. The fitted values of each parameter are shown in Table 12. 


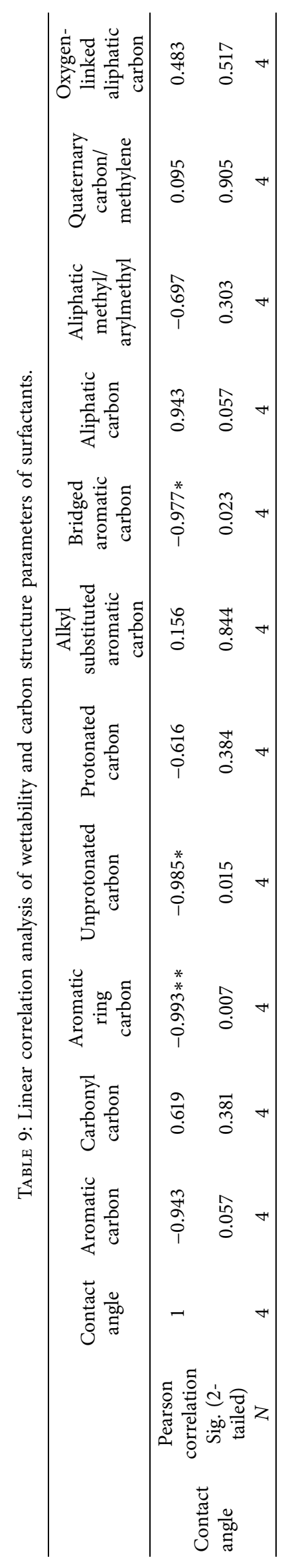


TABLE 10: Nonlinear correlation analysis of surfactant functional groups and wettability.

\begin{tabular}{lcc}
\hline Factor & Fitting formula & $R^{2}$ \\
\hline Carbonyl carbon & $Y=33.01+6.26 x-0.52 x^{2}$ & 0.51910 \\
Protonated carbon & $Y=46.05-25.44 x+4.58 x^{2}$ & 0.98663 \\
Aliphatic methyl/arylmethyl & $Y=-227.25+138.17 x-17.17 x^{2}$ & 0.99868 \\
Quaternary carbon/methylene & $Y=84.47-2.6 x+0.03 x^{2}$ & 0.46883 \\
Oxygen-linked aliphatic carbon & $Y=-33.41+3.9 x-0.04 x^{2}$ & 0.71263 \\
\hline
\end{tabular}

TABle 11: Assignment of variables in the model of evaluating the wettability of surfactants to bituminous coal dust.

\begin{tabular}{cccccccc}
\hline Hydroxyl & $\begin{array}{c}\text { Aromatic ring } \\
\text { carbon }\end{array}$ & $\begin{array}{c}\text { Unprotonated } \\
\text { carbon }\end{array}$ & $\begin{array}{c}\text { Bridged aromatic } \\
\text { carbon }\end{array}$ & $\begin{array}{c}\text { Ether } \\
\text { group }\end{array}$ & $\begin{array}{c}\text { Aliphatic methyl/ } \\
\text { arylmethyl }\end{array}$ & $\begin{array}{c}\text { Protonated } \\
\text { carbon }\end{array}$ & $\begin{array}{c}\text { Contact } \\
\text { angle }\end{array}$ \\
\hline$x_{1}$ & $x_{2}$ & $x_{3}$ & $x_{4}$ & $y_{1}$ & $y_{2}$ & $y_{3}$ & $Z$ \\
\hline
\end{tabular}

TABLE 12: Fitting results of parameters in the model of evaluating the wettability of surfactants to bituminous coal.

\begin{tabular}{lccccccccccc}
\hline Index & $a$ & $b$ & $c$ & $d$ & $e$ & $f$ & $g$ & $h$ & $i$ & $j$ \\
\hline V & 25.63 & -1.07 & -1.64 & 6.47 & -2.57 & 12.88 & 0.07 & 13.24 & -1.80 & -12.90 & 0.24 \\
S.E. & 12.07 & 0.04 & 0.28 & 1.01 & 0.39 & 2.88 & 0.14 & 5.69 & 0.67 & 2.68 & 0.14 \\
\hline
\end{tabular}

As shown in Table 12, the fitted model evaluating the factor influencing the wettability was

$$
\begin{aligned}
Z= & 25.63-1.07 * x_{1}-1.64 * x_{2}+6.47 * x_{3}-2.57 * x_{4} \\
& +12.88 * y_{1}-0.07 * y_{1}^{2}+13.24 * y_{2} \\
& -1.80 * y_{2}^{2}-12.90 * y_{3}+0.24 * y_{3}^{2} .
\end{aligned}
$$

\section{Conclusions}

Based on the FTIR and ${ }^{13} \mathrm{C}-\mathrm{NMR}$ experiments, the chemical microstructures of the bituminous coal and surfactants were obtained, and the relationship between the surfactant chemical microstructures and the ability of the surfactant to wet the bituminous coal dust was studied. The main conclusions obtained were as follows:

(1) According to the FTIR experiments results, the relative contents of the carbon-oxygen single bond, ether group, and hydroxyl group in the coal dust were relatively high. According to the ${ }^{13} \mathrm{C}-\mathrm{NMR}$ experiment results, the content of protonated aromatic carbon was the highest in the coal dust, followed by the methylene groups, quaternary carbon, bridged aromatic carbon, and oxygen-linked aliphatic carbon which were relatively low

(2) The wetting effect of cationic surfactant DDBAC on Tongchuan bituminous coal was the best. The contact angle of DDBAC on coal dust was $24.01^{\circ}$, much lower than that of FMEE, BS-12, and AEC

(3) The hydrophilicity of hydroxyl group was strong, and the correlation coefficient between its content and contact angle was -0.989 . As the content of hydroxyl in surfactant increases, the contact angle of surfactant droplet on coal sample dust decreases. According to the curve fitting results, the contact angle first decreased and then increased with the increase of ether group content

(4) Compared with other carbon compositions, the aromatic ring carbon has the highest correlation coefficient with contact angle, which was -0.993 . The contact angle decreased with the increase of aromatic carbon in surfactants. The influence of the bridge aromatic carbon and the unprotonated carbon on the contact angle was similar to that of the aromatic ring carbon

(5) For the bituminous coal dust used in the experiment, the contents of hydroxyl, aromatic carbon, unprotonated carbon, ether group, methyl group, and protonated carbon in the surfactants were the key factors of affecting contact angles. The fitted wetting model was expressed as $Z=25.63-1.07 \times$ hydroxyl $-1.64 \times$ aromatic ring carbon $+6.47 \times$ unprotonated carbon $-2.57 \times$ bridge aromatic carbon $+12.88 \times$ ether group $-0.07 \times$ ether group $2+13.24 \times($ aliphatic methyl + arylmethyl $)-$ $1.80 \times(\text { aliphatic methyl }+ \text { arylmethyl })^{\wedge}$ $2-12.90 \times$ protonated carbon $+0.24 \times$ protonated carbon 2

\section{Data Availability}

FTIR, 13 C-NMR, and the device types used for recording spectra used to support the findings of this study are included within the article.

\section{Conflicts of Interest}

The authors declare that there are no conflicts of interest regarding the publication of this paper. 


\section{Acknowledgments}

This work was financially supported by the National Natural Science Foundation of China (no. 51804034) and the Key Research and Development Plan Project in Shandong Province (no. 2019GSF111034).

\section{References}

[1] G. Zhou, Q. Zhang, R. Bai, T. Fan, and G. Wang, "The diffusion behavior law of respirable dust at fully mechanized caving face in coal mine: CFD numerical simulation and engineering application," Process Safety and Environmental Protection, vol. 106, pp. 117-128, 2017.

[2] J. Wang, G. Zhou, X. Wei, and S. Wang, "Experimental characterization of multi-nozzle atomization interference for dust reduction between hydraulic supports at a fully mechanized coal mining face," Environmental Science and Pollution Research, vol. 26, no. 10, pp. 10023-10036, 2019.

[3] A. P. Nordin, J. Da Silva, C. T. De Souza et al., "In vitro genotoxic effect of secondary minerals crystallized in rocks from coal mine drainage," Journal of Hazardous Materials, vol. 346, pp. 263-272, 2018.

[4] Q. Zhang, G. Zhou, X. Qian, M. Yuan, Y. Sun, and D. Wang, "Diffuse pollution characteristics of respirable dust in fullymechanized mining face under various velocities based on CFD investigation," Journal of Cleaner Production, vol. 184, pp. 239-250, 2018.

[5] S. Li, G. Zhou, Y. Wang, B. Jing, and Y. Qu, "Synthesis and characteristics of fire extinguishing gel with high water absorption for coal mines," Process Safety and Environmental Protection, vol. 125, pp. 207-218, 2019.

[6] W. Han, G. Zhou, D. Gao et al., "Experimental analysis of the pore structure and fractal characteristics of different metamorphic coal based on mercury intrusion-nitrogen adsorption porosimetry," Powder Technology, vol. 362, pp. 386-398, 2020 .

[7] G. Zhou, Q. Zhang, Y. Hu, D. Gao, S. Wang, and B. Sun, "Dust removal effect of negatively-pressured spraying collector for advancing support in fully mechanized coal mining face: numerical simulation and engineering application," Tunnelling and Underground Space Technology, vol. 95, Article ID 103149, 2020

[8] W. Han, G. Zhou, Q. Zhang, H. Pan, and D. Liu, "Experimental study on modification of physicochemical characteristics of acidified coal by surfactants and ionic liquids," Fuel, vol. 266, Article ID 116966, 2020.

[9] S. Li, G. Zhou, Z. Liu, N. Wang, Z. Wei, and W. Liu, "Synthesis and performance characteristics of a new ecofriendly crustdust suppressant extracted from waste paper for surface mines," Journal of Cleaner Production, vol. 258, Article ID 120620, 2020.

[10] W. Yin, G. Zhou, and D. Gao, "Simulation analysis and engineering application of distribution characteristics about multi-stage atomization field for cutting dust infully mechanized mining face," Advanced Powder Technology, vol. 30, no. 11, pp. 2600-2615, 2020.

[11] M. Wu, X. Hu, Q. Zhang, D. Xue, and Y. Zhao, "Growth environment optimization for inducing bacterial mineralization and its application in concrete healing," Construction and Building Materials, vol. 209, pp. 631-643, 2019.

[12] R. Liu, G. Zhou, C. Wang, W. Jiang, and X. Wei, "Preparation and performance characteristics of an environmentallyfriendly agglomerant to improve the dry dust removal effect for filter material," Journal of Hazardous Materials, vol. 397, Article ID 122734, 2020.

[13] T. Fan, G. Zhou, and J. Wang, "Preparation and characterization of a wetting-agglomeration-based hybrid coal dust suppressant," Process Safety and Environmental Protection, vol. 113, pp. 282-291, 2018.

[14] Y. Ma, G. Zhou, J. Ding, S. Li, and G. Wang, "Preparation and characterization of an agglomeration-cementing agent for dust suppression in open pit coal mining," Cellulose, vol. 25, no. 7, pp. 4011-4029, 2018.

[15] D. W. Guy, R. J. Crawford, and D. E. Mainwaring, "The wetting behaviour of several organic liquids in water on coal surfaces," Fuel, vol. 75, no. 2, pp. 238-242, 1996.

[16] E. S. A. Halim and S. S. A. Deyab, "Chemically modified cellulosic adsorbent for divalent cations removal from aqueous solutions," Carbohydrate Polymers, vol. 87, no. 2, pp. 1863-1868, 2012.

[17] G. Zhou, Y. Ma, T. Fan, and G. Wang, "Preparation and characteristics of a multifunctional dust suppressant with agglomeration and wettability performance used in coal mine," Chemical Engineering Research and Design, vol. 132, pp. 729-742, 2018.

[18] G. Ni, Q. Sun, M. Xun et al., "Effect of NaCl-SDS compound solution on the wettability and functional groups of coal," Fuel, vol. 257, Article ID 116077, 2019.

[19] G. Wang, T. Huang, S. Yan, and X. Liu, "Experimental study of the fracturing-wetting effect of VES fracturing fluid for the coal seam water injection," Journal of Molecular Liquids, vol. 295, Article ID 111715, 2019.

[20] P. Wang, H. Han, C. Tian, R. Liu, and Y. Jiang, "Experimental study on dust reduction via spraying using surfactant solution," Atmospheric Pollution Research, vol. 11, no. 6, pp. 3242, 2020.

[21] C. Xu, D. Wang, H. Wang et al., "Experimental investigation of coal dust wetting ability of anionic surfactants with different structures," Process Safety and Environmental Protection, vol. 121, pp. 69-76, 2019.

[22] X. Wang, S. Yuan, and B. Jiang, "Experimental investigation of the wetting ability of surfactants to coals dust based on physical chemistry characteristics of the different coal samples," Advanced Powder Technology, vol. 30, no. 8, pp. 1696-1708, 2019. 